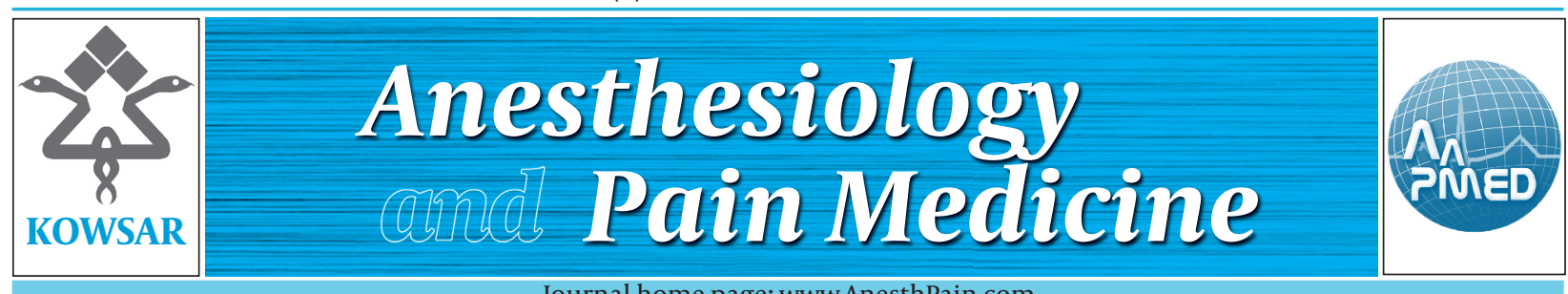

\title{
Minimally Invasive Percutaneous Techniques for the Relief of Pain in Lumbar Disc Disease
}

\author{
$\operatorname{Tariq}_{\text {Sinan }}{ }^{1^{*}}$, Mehraj Sheikh $^{2}$ \\ ${ }^{1}$ Department of Radiology, Kuwait University Health Sciences Center, Jabriya, Kuwait \\ ${ }^{2}$ Department of Radiology, Kuwait University and Mubarak Al-Kabeer Teaching Hospital, Jabriya, Kuwait
}

A R T I C L E I N F O

\section{Article Type:}

Letter to Editor

Article history:

Received: 16 Aug 2011

Revised: 19 Aug 2011

Accepted: 25 Aug 2011

\section{Keywords:}

Pain

Back pain

Disk prolapse

\section{Dear Editor,}

Alleviation of back pain and/or any disability due to pain in patients with lumbar disc disease undoubtedly gives a sense of relief and well being. The use of noninvasive or minimally invasive interventional procedures for this condition is basically aimed at limiting pain and disability. A number of such minimally invasive percutaneous techniques for the treatment of lumbar disc disease have been developed over the years, with the common tenet being the ability to act directly on the disc content without violating the spinal channel or increasing subsequent risk of scarring.

Electrosurgical technology has been developed for use in the spine and possesses few, if any of the drawbacks of the other percutaneous disc decompression techniques. These are usually plasma-mediated radiofrequencybased excision and allow precise etching of tissue. When

\footnotetext{
* Corresponding author: Tariq Sinan, Department of Radiology, Kuwait University Health Sciences Centre, Jabriya, Kuwait. Tel: +965-99593101, Fax: +965-25330473, E-mail: drtariq999@yahoo.com

DOI: 10.5812/kowsar.22287523.2102

Copyright @2011, ISRAPM, Published by Kowsar Corp.
}

Please cite this paper as:

Sinan T, Sheikh M. Minimally Invasive Percutaneous Techniques for the Relief of Pain in Lumbar Disc Disease. Anesth Pain. 2011;1(2):109-10.

DOI: $10.5812 /$ kowsar.22287523.2102

Copyright @ 2011, ISRAPM, Published by Kowsar Corp.

used for tissue ablation (excision) in the disc, these procedures excise target material without gross thermal or structural damage to adjacent tissue (1).

We have studied patients using the nucleoplasty procedure developed by Arthro Care Corporation (Sunnyvale, CA), which is performed using a plasma-mediated radiofrequency-based device. This procedure uses radiofrequency to excite the electrolytes in a conductive medium, such as saline solution, to create precisely focused plasma. The energized particles in the plasma have sufficient energy to break molecular bonds, excising or dissolving soft tissue at relatively low temperatures (2-4). In our study (5) on 83 patients the majority of patients reported substantial pain relief within one month following the nucleoplasty discectomy, with the majority of them reporting minimal or no pain or disability and satisfaction with results after one year. Our experience revealed that nucleoplasty discectomy is a suitable, minimally invasive technique that could be considered a valid alternative to surgery when evaluating possible treatment options in patients affected by contained lumbar disc herniation. It appears particularly indicated for patients that have exhausted other conservative treatment modalities but have not yet reached clear-cut indications 
for open surgical treatment and in such patients it could be safe to give it a trial.

Two main mechanisms are reported as possibly being the basis of the effect of percutaneous disc decompression. Mechanical decompression of the nucleus pulpous with partial emptying of the disc space with consequent pressure lowering inside the disc space is considered as a mechanical explanation of the procedure (6). The other mechanism that has been hypothesized is a chemical disruption of degenerative metabolic processes inside the disc space which may induce changes in disc metabolism related to inflammation and/or initiate an autoimmune response in surrounding tissue to affect pain symptomatology (7-9). Based on these hypothesis it is postulated that nucleoplasty can be performed on patients with non-contained disc prolapse as well and that too at higher energy levels, unlike that of our study where it was done on selected patients with contained disc prolapse.

Farzanegan et al. (10) in a study published in this journal showed that pain relief after laminectomy, which is a major surgical procedure, for lumbar disc protrusion resulted in improvements in the mental depression that was associated with pain. The main difference between their study and ours was our study advocates the use of nucleoplasty, a non-invasive procedure, for pain relief. In summary, our studies, in conjunction to the study reported in this journal lend credence to the fact that pain relief, which is essential to the physical and mental well being of patients, should be acquired at least initially by non-invasive or minimally invasive procedures, and therefore we recommend nucleoplasty as an initial methodology for alleviation of back pain.

\section{Financial Disclosure}

None declared.

\section{References}

1. Chen YC, Lee SH, Saenz Y, Lehman NL. Histologic findings of disc, end plate and neural elements after coblation of nucleus pulposus: an experimental nucleoplasty study. Spine J. 2003;3(6):46670 .

2. Stalder KR, Woloszko J, Brown IG, Smith CD. Repetitive plasma discharges in saline solutions. Appl phys lett. 2001;79(27):4503-5.

3. Woloszko J, Stalder KR, Brown IG. Plasma characteristics of repetitively-pulsed electrical discharges in saline solutions used for surgical procedures. IEEE Trans Plasma Sci. 2002;30(3):1376-83.

4. Stalder KR, McMillen DF, Woloszko J. Electrosurgical plasmas. J Phys D Appl Phys. 2005;38:1728.

5. Sinan T, Sheikh M, Buric J, Dashti K, Al-Mukhaimi A. Percutaneous coblation nucleoplasty in patients with contained lumbar disc prolapse: 1 year follow-up in a prospective case series. Acta Neurochir Suppl. 2011;108:107-12.

6. Chen C, Cavanaugh JM, Song Z, Takebayashi T, Kallakuri S, Wooley PH. Effects of nucleus pulposus on nerve root neural activity, mechanosensitivity, axonal morphology, and sodium channel expression. Spine (Phila Pa 1976). 2004;29(1):17-25.

7. Kobayashi S, Yoshizawa H, Yamada S. Pathology of lumbar nerve root compression. Part 1: Intraradicular inflammatory changes induced by mechanical compression. J Orthop Res. 2004;22(1):170-9.

8. Kobayashi S, Yoshizawa H, Yamada S. Pathology of lumbar nerve root compression. Part 2: morphological and immunohistochemical changes of dorsal root ganglion. J Orthop Res. 2004;22(1):180-8.

9. Kawakami M, Tamaki T, Hayashi N, Hashizume H, Nishi H. Possible mechanism of painful radiculopathy in lumbar disc herniation. Clin Orthop Relat Res. 1998(351):241-51.

10. Farzanegan G, Alghasi M, Safari S, Ahmadi SA. Effects of lumbar discectomy on disability and depression in patients with chronic low back pain. Anesth Pain. 2011;1(1):20-4. 